Covered in: Web of Sciences (WOS); EBSCO; ERIH+; Google Scholar; Index Copernicus; Ideas RePeC; Econpapers; Socionet; CEEOL; Ulrich ProQuest; Cabell, Journalseek; Scipio; Philpapers; SHERPA/RoMEO repositories; KVK; WorldCat; CrossRef; CrossCheck

\section{The Evolution of Human Values - A Comparative Study of Values in Adolescents and Emerging Adults}

\section{Claudia SĂLCEANU1}

${ }^{1}$ Lecturer PhD, Ovidius University of Constanța, Constanța, România, claudiasalceanu@yahoo.com
Abstract: From pre-history to present days, the evolution of human culture implied the evolution of human values as well. During their lifetime, people develop a set of values and accept certain standards or norms by which their conduct is judged. Although the development of values starts in the early childhood, is not until adolescence that a person builds and defines his or hers own set of values and principles. A sample of 1250 participants, between 16 and 25 years of age, has been assessed with a V21 Questionnaire of Values, from Cognitrom Assessment System. The objectives and hypotheses of the study highlight the existence of differences between the evolution of human values in adolescence and emerging adulthood, based on certain demographic variables, like gender, age, provenience and level of studies. We discovered some statistically significant differences, such as: (1) women value professional recognition, social relationships, autonomy, safety, compliance to rules and challenges, more than men; (2) university students value autonomy more than high-school students; (3) people in urban areas value autonomy more than those in rural areas; (4) emerging adults value autonomy more than teenagers. In the end of the study, there is a debate on the conclusions and practical implication of this research.

Keywords: Human values; evolution; adolescents; emerging adults.

How to cite: Sălceanu, C. (2019). The Evolution of Human Values - A Comparative Study of Values in Adolescents and Emerging Adults. Postmodern Openings, 10(2), 74-83. doi:10.18662/po/72 



\section{Introduction}

From pre-history to present days, the evolution of human culture also implied the evolution of human values, which can be considered the foundation of human development. Today's society is characterized by accelerated socio-economic and technological changes to which people have to adjust. Most of the social problems in our society can be closely related to values (Türkkahraman, 2014).

Many researchers highlight the fact that values are a central construct for many psychological, social and humanistic sciences (Fleishman, 2013; Jones, Shaw, Ross, Witt \& Pinner, 2016; Mayton II, Loges \& Ball-Rokeach, 1994; Patil, Thombare \& Kharade, 2016; Sagiv, Roccas, Cieciuch \& Schwartz, 2017).

\section{Human values and adolescence}

Values refer to abstract beliefs which serve as guidelines (Kesberg \& Keller, 2018). They are ways of understanding the self and the world (Goodale, 2016). Values are the foundations of human behavior, playing the role of selection criteria for individuals in their own environment (Deth \& Scarbrough, as cited in Sălceanu, 2014), as they are also crucial for people to live in harmony around the world (Hazaea, Ibrahim \& Mohd Nor, 2014).

Rokeach (1968) considers that values represent the main axis of orientation of the whole personality. Each individual has an organized hierarchical system of values, that guides him throughout his entire lifespan. Furthermore, Rokeach states that values are basically thoughts that have an emotional load related to objects, ideas or behaviors.

Since the concept of values is difficult to define, and there is actually no unanimous sense in their description, it is important to emphasize five atributes of values that Van Deth \& Scarborough (1994, as cited in Voicu, 2010) identified as benefitting of a certain consensus between different authors: (1) they exist, but don't always manifest; (2) they are conceptions of the desirable and relate to different hierarchies and preferences; (3) they are relatively stable; (4) they can manifest through behaviors, attitudes and beliefs; (5) they have a certain social causality.

Researchers state that values are mental processes, both cognitive and emotional. They combine representations, concepts, goals and beliefs with the positive or negative valences of emotional attitudes (Thagard, 2013). The author also states that neurosciences conceptualize values as neural processes, which are defined as correct or incorrect, based on how much they agree with human needs. 
In order to better understand the evolution of values during adolescence and emerging adulthood, it's important to highlight few characteristics of this stage of development. Adolescence is the stage of transition from childhood to adulthood (Sion, 2007), characterized by physical, cognitive, emotional and social major changes. The main developmental tasks in adolescence include (Rose, 2012): (1) making the transition from the safety of the family and school, towards society, people and new ideas; (2) accepting the physical changes and intregrating the information into a positive self-image; (3) gaining personal authonomy, trusting their own judgements and actions, acknowledging their own responsibility; (4) obtaining intimacy with others and establishing a secure sexual identity; (5) adapting to the adults' professional responsibilities, carrying about others, acknowledging the commitment.

Values are guiding standards of adolescents' life and can influence which behaviors are more justified than others (Benish-Weisman, 2015). Adolescents are capable of learning values and of acting accordingly (Golu, 2000, as cited in Crețu, 2009). At individual level, these values are systemathised in a very personal way and have different significance, intensity and orientative function. The moral evolution in adolescence is based on the development of formal thinking, which allows teenagers to better judge the norms and the values they've internalised during their childhood (Adams \& Berzonsky, 2009).

Sociologist Morris Massey („Values development”, n.d.) speaks about three major periods of development of values: (1) the imprint period - from birth to the age of seven, when children accept everything as true, especially when it comes from their parents; (2) the modeling period - from eight to thirteen, when children copy their models; (3) the socialization period from thirteen to twentyone, when people are largely influenced by their peers.

Dose (1997) emphasizes the fact that values are developed under the influence of culture, society and personality. Furthermore, they tend to reflect the values of society and of the period of time during which an individual has reached maturity.

\section{Aim of the research and hypotheses}

The main objective of the research is to identify whether there are statistically significant differences between participants regarding their value systems, based on certain demographic variables: gender, age, residence and level of studies. 
The hypotheses of the study are: (1) We presume there are significant differences between male and female regarding value systems; (2) We presume there are significant differences between adolescents and emerging adults regarding value systems; (3) We presume there are significant differences between participants residing in urban areas and participants residing in rural areas regarding value systems; (4) We presume there are significant differences between high-school students and university students regarding value systems.

\section{Sample and research methods}

The sample consisted in 1250 adolescents, aged between 16 and 25 years, 804 female and 446 male, 547 high-school students and 703 university students, 845 with urban residence and 405 with rural residence, 475 adolescents (15-19 years) and 783 emerging adults (20-25 years). To ensure the ethics of the research, we obtained from all the participants their written consent, as well as the permission from parents and schools chairman to conduct the study.

The sample has been assessed with V21 Questionnaire of Values, from Cognitrom Assessment System, which is centred on nine personal values that can be relevant for counselling and vocational orientation of students: skill development, professional recognition, authority, social relationships, autonomy, safety, compliance with rules, challenge and free time.

\section{Findings and results}

H1: We presume there are significant differences between male and female regarding value systems. We used Mann-Whitney U Test and we obtained significant differences between male and female regarding professional recognition $(\mathrm{p}=.000)$, social relationships $(\mathrm{p}=.000)$, autonomy $(\mathrm{p}=.001)$, safety $(\mathrm{p}=.024)$, compliance with rules $(\mathrm{p}=.000)$ and challenge $(p=.005)$. The mean rank of the female sample was significantly higher than that of the male sample.

H2: We presume there are significant differences between adolescents and emerging adults regarding value systems. We obtained significant differences between adolescents and emerging adults regarding autonomy $(\mathrm{p}=.000)$. The mean rank of the adolescent sample was significantly lower than that of the emerging adults.

H3: We presume there are significant differences between participants residing in urban areas and participants residing in rural areas 
regarding value systems. We obtained significant differences regarding autonomy $(\mathrm{p}=.001)$. The mean rank of the participants residing in urban areas was significantly higher than that of the participants residing in rural areas.

H4: We presume there are significant differences between highschool students and university students regarding value systems. We obtained significant differences regarding autonomy $(\mathrm{p}=.029)$. The mean rank of university students was significantly higher than that of the highschool students.

\section{Discussion}

The results of the first hypothesis highlight that women value professional recognition more than men. Because men and women stereotypically have different roles and although women have made great strides in the workplace, inequality still persists, according to Harvard Summer School ("Gender Inequality and Women in the Workplace", n.d.). Although women have, in some cases, even surpass men in educational achievements, the problem of inequality rises when young adults try to balance work and family, and women end up carrying for nearly all of the household's responsibilities. Zimmerman (2016) states that often, women have to put up more effort into their work, in order to achieve professional recognition. This situation in encountered in many fields, like health and engineering (Vieira, de Pádua Carrieri, Reis Monteiro \& Ferreira Roquete, 2017) or corporate-board membership or executive-committee membership (Devillard, Hunt \& Yee, 2018). The fact that women value career success and recognition more than men, while they also report less time for career progress, is also emphasized by a study conducted by Buckley, Sanders, Shih \& Kallar (2000).

Another discovery shows that women value social relationships more than men. It seems it's important for women to build, develop and maintain pleasant and uncompetitive relationships with people they have contact with, in school, workplace or any other field. Women use communication as an instrument that allows them to enhance social connections and create relationships (Leaper, 1991; Maltz \& Borker, 1982; Mason, 1994; Wood, 1996). A study conducted by David-Barrett, Rotkirch, Carney, Behncke Izquierdo, Krems, Townley, McDaniell, Byrne-Smith \& Dunbar (2015) shows that it's important for women to maintain these close relationships once they leave their natal group, because these bonds are crucial for accessing resources. Furthermore, it seems women have better 
understood the importance of good working relationships with their colleagues as an important factor of professional praise and recognition.

Autonomy is more important to women than men (H1), to emerging adults than adolescents (H2), to residents of the urban areas than to residents of the rural areas (H3) and to university students than to highschool students (H4). Autonomy is the capacity of self-governance (Hmel \& Pincus, 2002). It means freedom and diversity of action, it is the ability to make own choices and to plan according to own standards and principles. Autonomy in adolescence and emerging adulthood can be developed through removal from parental constraints and control, cooperation, emotional detachment from parents and peers, personal development and an integrated self-identity, individualization, gaining the responsibility of the own life, actions, decisions and behaviours.

It seems that women's autonomy in decision making is positively associated with their age and employment (Acharya, Bell, Simkhada, van Teijlingen \& Regmi, 2010), to their educational level (Khatwani, 2017), to the specific decision domain (Research Program on Policies, Institutions and Markets, 2018). Outside mobility, access to economic resources and involvement in household decisions are dimensions of autonomy which are positively associated with socio-economic and demographic factors (Khan \& Ram, 2009). People living in rural areas have less autonomy in decision making, due to their socio-economic status. Many low-income societies have strong social structures that rigidly define the roles of men and women, usually encoded in religious and social traditions (Osamor \& Grady, 2016). In urban areas, people are more likely to make decisions in their own health care, leisure, work activities, to purchase daily household needs, as there is also a higher level of education.

Another significant difference we discovered is related to safety. Is seems women value certainty more than men, they feel it's important to seek and participate in activities in which the outcome is secure, the rules and factors are known, the consequences can be assessed. Studies show that at neural level, uncertainty causes a strong threat or alert response in people's limbic system. This means that the brain reacts to uncertainty as it would to any type of pain that should be avoided (Rock, 2009). Obviously, due to their roles in society, women tend to care more about keeping their jobs, having enough money or their children being healthy. And that is strong emotional load. Although life is filled with twists and turns, which cannot be controlled, the need to feel secure, to know what will happen next, is an important aspect of women's life. 
In relation to this certainty they need, women also value compliance to rules more than men, and this is partially because of their upbringing. Parents, especially fathers, tend to be more rigorous with girls, they establish norms and boundaries. Nevertheless, studies show that the psychological support from the parents is strongly correlated with high self-esteem and wellbeing in adolescence (Siddique \& D'Arcy, 1984, as cited in Hoffman, Ushpiz \& Levy-Shiff, 1988). So, internalising values and behaviours during childhood is the foundation of the autonomy in adolescence, since this process helps the adolescent to develop his own identity. Still, gaining distance from the parental styles and patterns is a great achievement for Romanian adolescent girls, because Romanian families tend to be quite traditional and patriarchal.

Finally, related to professional recognition, women value challenge more than men. Challenges require a great level of strategic complexity regarding planning, achieving and monitoring. Challenges offer the perfect opportunity to prove someone's skills, competences or abilities.

\section{Conclusions}

The findings of this study are important for many reasons, as they offer an image of the evolution of values in adolescence and emerging adulthood, useful for parents, teachers and professionals working in the field vocational and family counselling. It is important to create a proper framework for the development of adolescents and emerging adults. The one value that emerges, from the entire research, as being truly important is autonomy. This provides a goal for further studies about the development of autonomy in adolescence.

\section{References}

Acharya, D. R., Bell, J. S., Simkhada, P., van Teijlingen, E. R., \& Regmi, P. R. (2010). Women's autonomy in household decision-making: a demographic study in Nepal. Reproductive Health, 7(15). doi:10.1186/1742-4755-7-15

Adams, G. R., \& Berzonsky, M. D. (coords.), (2009). Psibologia adolescenței. Manualul Blackwell. Iasi: Ed. Polirom

Benish-Weisman, M. (2015). The Interplay between Values and Aggression in Adolescence: A Longitudinal Study. Developmental Psychology, 51(5), 1-43, doi:10.1037/dev0000015

Buckley, L. M., Sanders, K. M., Shih, M., \& Kallar, S. (2000). Obstacles to Promotion? Values of Women Faculty about Career Success and 
The Evolution of Human Values - A Comparative Study of Values in ... Claudia SĂLCEANU

Recognition. Academic Medicine, 75(3), 282-288. doi:10.1097/00001888200003000-00021

Crețu, T. (2009). Psihologia vârstelor, 3rd edition. Iaşi: Ed. Polirom

David-Barrett, T., Rotkirch, A., Carney, J., Behncke Izquierdo, I., Krems, J.A., Townley, D., McDaniell, E., Byrne-Smith, A., Dunbar, R.I.M. (2015).

Women Favour Dyadic Relationships, but Men Prefer Clubs: CrossCultural Evidence from Social Networking. PLoS One, 10(3). doi:10.1371/journal.pone.0118329

Devillard, S., Hunt, V., \& Yee, L. (2018). Still looking for room at the top: Ten years of research on women in the workplace. McKinsey Quarterly, March 2018. Retrieved from https://www.mckinsey.com/featuredinsights/gender-equality/still-looking-for-room-at-the-top-ten-years-ofresearch-on-women-in-the-workplace, accessed on 30.01.2019

Dose, J. J. (1997). Work values: An integrative framework and illustrative application to organizational socialization. Journal of Occupational and Organizational Psychology, 70(3), 219-240, doi:10.1111/j.20448325.1997.tb00645.x

Fleishman, K. R. (2013). Information and Human Values. Synthesis Lectures on Information Concepts, Retrieval, and Services, 5(5), 1-99, doi:10.2200/S00545ED1V01Y201310ICR031

Goodale, M. (2016). Human values and moral exclusion. Journal of Ethics \& Global Politics, 9(1), 1-13. doi:10.3402/egp.v9.32957

Hazaea, A., Ibrahim, N., \& Mohd Nor, N. F. (2014). Dissemination of Human Values: Discourse Analysis of Global Educational Media Texts. ProcediaSocial and Behavioral Sciences, 118, 166-171, doi:10.1016/j.sbspro.2014.02.022

Hmel, B. A., \& Pincus, A. L. (2002). The meaning of autonomy: on and beyond the interpersonal circomplex. Journal of Personality, 70, 277-308.

Hoffman, M. A., Ushpiz, V., \& Levy-Shiff, R. (1988). Social support and selfesteem in adolescence. Journal of Youth and Adolescence, 17(4), 307-316.

Jones, N. A., Shaw, S., Ross, H., Witt, K, \& Pinner, B. (2016). The study of human values in understanding and managing social-ecological systems. Ecology and Society, 21(1), 15. doi:10.5751/ES-07977-210115

Khan, N., \& Ram, U. (2009). Can women's perceptions of their own autonomy enable them to generate changes in their reproductive behavior? Evidences from gender perspectives.

Retrieved from https://paa2009.princeton.edu/papers/91915, accessed on 30.01.2019

Khatwani, M.K. (2017). Professional Women's Experience of Autonomy and Independence in Sindh-Pakistan. London: IntechOpen. Retrieved from https://www.intechopen.com/books/gender-differences-in-differentcontexts/professional-women-s-experience-of-autonomy-andindependence-in-sindh-pakistan, accessed on 30.01.2019 
Kesberg, R., \& Keller, J. (2018). The Relation Between Human Values and Perceived Situation Characteristics in Everyday Life. Frontiers in Psychology, 9(1676). doi:10.3389/fpsyg.2018.01676

Leaper, C. (1991). Influence and involvement in children's discourse: Age, gender and partner effects. Child Development, 62, 797-811.

Maltz, D. N., \& Borker, R. (1982). A cultural approach to male-female miscommunication. In Gumpertz, J.J. (Ed.), Language and social identity (pp.196-216). Cambridge: Cambridge University Press.

Mason, E. S. (1994). Gender differences in job satisfaction. The Journal of Social Psychology, 135, 143-151.

Mayton II, D. M., Loges, W. E., \& Ball-Rokeach, S. J. (1994). Human Values and Social Issues: An Introduction. Journal of Social Issues, 50(4), 1-8, doi:10.1111/j.1540-4560.1994.tb01194.x

Osamor, P. E., \& Grady, C. (2016). Women's autonomy in health care decisionmaking in developing countries: a synthesis of the literature. International Journal of Women's Health, 8, 191-202, doi:10.2147/IJWH.S105483

Patil, J. R., Thombare, D. G., \& Kharade, R. A. (2016). The Importance and Need of Universal Human Values in Engineering Student's Life. Compass, 10(1), 102-105.

Rock, D. (2009). A Hunger for Certainty. Your brain craves certainty and avoids uncertainty like it's pain. Your Brain ar Work. Retrieved from https://www.psychologytoday.com/us/blog/your-brainwork/200910/hunger-certainty, accessed on 30.01.2019

Rokeach, M. (1968). Beliefs, attitudes, and values: a theory of organization and change. San Francisco: Jossey-Bass.

Rose, J. (2012). Adolescența. In Rayner, E., Joyce, A., Rose, J., Twyman, M. \& Clulow, C. (coords.). Psibodinamica de zvoltării umane. Creștere, maturitate, senectute (pp. 246-321). Bucureşti: Ed. Trei.

Savig, L., Roccas, S., Cieciuch, J., \& Schwartz, S. (2017). Personal values in human life. Nature Human Behaviour, 1, 630-639.

Sălceanu, C. (2014). Thinking Styles and Moral Values in Adulthood. Postmodern Openings, 5(4), 91-99. doi:10.18662/po/2014.0504.07

Sion, G. (2007). Psibologia vârstelor, 4th edition. București: Ed. Fundației România de Mâine.

Thagard, P. (2013). What are Values? Values are mind-brain processes that combine cognition and emotion. Hot Thought. Retrieved from https://www.psychologytoday.com/intl/blog/hot-thought/201304/whatare-values (accessed on 29.01.2019)

Türkkahraman, M. (2014). Social values and value education. Procedia - Social and Behavioral Sciences, 116(2014), 633-638. doi:10.1016/j.sbspro.2014.01.270 
The Evolution of Human Values - A Comparative Study of Values in ... Claudia SĂLCEANU

Vieira, A., de Pádua Carrieri, A., Reis Monteiro, P. R., \& Ferreira Roquete, F. (2017). Gender Differences and Professional Identities in Health and Engineering. BAR - Brazilian Administration Review, 14(1). doi:10.1590/1807-7692bar2017160082

Voicu, B. (2010). Valorile şi sociologia valorilor. In L. Vlăsceanu, (coord.), Sociologie (pp. 249-294). Iaşi: Ed. Polirom

Wood, J. T. (1996). Gendered lives: Communication, gender and culture (2nd edition). Belmont, CA: Wadsworth.

Zimmerman, K. (2016). What Gender Barriers Do Millennial Women Face In The Workplace? Forbes. Retrieved from

https://www.forbes.com/sites/kaytiezimmerman/2016/08/18/whatgender-barriers-do-millennial-women-face-in-theworkplace/\#4a3e3621604c, accessed on 30.01.2019

Values Development. (n.d.). Retrieved from

http://changingminds.org/explanations/values/values development.htm, accessed on 29.01.2019

Harvard Summer School. (n.d.). Gender Inequality and Women in the Workplace.

Retrieved from https://www.summer.harvard.edu/inside-summer/genderinequality-women-workplace, accessed on 30.01.2019

Research program on Policies, Institutions and Markets. (2018). New paper of relationship between autonomy and decision making contributes to understanding and measurement of women's empowerment. Retrieved from http://pim.cgiar.org/2018/08/07/new-paper-on-relationship-betweenautonomy-and-decision-making-contributes-to-understanding-andmeasurement-of-womens-empowerment/, accessed on 30.01.2019 